\title{
Thermally-driven Flow in a Cavity Using the Galerkin Finite Element Method
}

\author{
K.W. Westerberg
}

This article was submitted to

First M.I.T. Conference on Computational Fluid and Solid Mechanics Cambridge, MA, June 12-14, 2001

\section{October 19, 2000}

U.S. Department of Energy

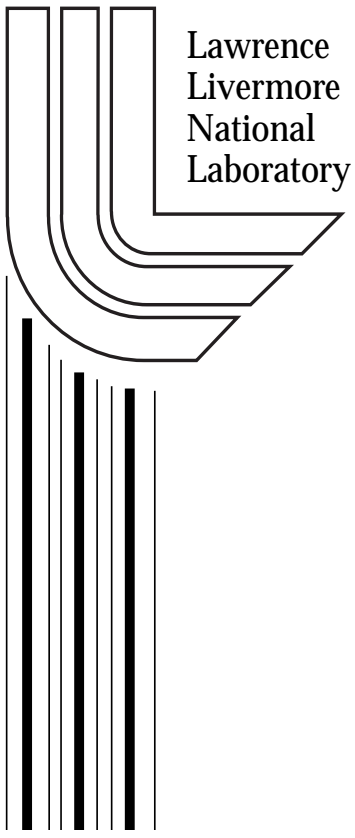




\section{DISCLAIMER}

This document was prepared as an account of work sponsored by an agency of the United States Government. Neither the United States Government nor the University of California nor any of their employees, makes any warranty, express or implied, or assumes any legal liability or responsibility for the accuracy, completeness, or usefulness of any information, apparatus, product, or process disclosed, or represents that its use would not infringe privately owned rights. Reference herein to any specific commercial product, process, or service by trade name, trademark, manufacturer, or otherwise, does not necessarily constitute or imply its endorsement, recommendation, or favoring by the United States Government or the University of California. The views and opinions of authors expressed herein do not necessarily state or reflect those of the United States Government or the University of California, and shall not be used for advertising or product endorsement purposes.

This is a preprint of a paper intended for publication in a journal or proceedings. Since changes may be made before publication, this preprint is made available with the understanding that it will not be cited or reproduced without the permission of the author.

This report has been reproduced directly from the best available copy.

Available to DOE and DOE contractors from the

Office of Scientific and Technical Information

P.O. Box 62, Oak Ridge, TN 37831

Prices available from (423) 576-8401

http:/ / apollo.osti.gov/bridge/

Available to the public from the National Technical Information Service

U.S. Department of Commerce 5285 Port Royal Rd., Springfield, VA 22161 http://www.ntis.gov/

OR

Lawrence Livermore National Laboratory Technical Information Department's Digital Library http://www.llnl.gov/tid/Library.html 


\title{
Thermally-driven Flow in a Cavity
}

\section{Using the Galerkin Finite Element Method}

\author{
K.W. Westerberg \\ Lawrence Livermore National Laboratory \\ 7000 East Ave., L-091, Livermore, CA 94550, U.S.A.
}

\section{Abstract}

Time periodic solutions are found for the natural convection of a $\operatorname{Pr}=0.71$ fluid in a differentially heated $8 \times 1$ cavity at $R a=3.4 \times 10^{5}$ using a "straight" Galerkin finite element method with the $Q_{2} Q_{1}$ element. Time integration is performed with an implicit second-order accurate (in time) trapezoid rule. As expected, the average values of various solution metrics were relatively insensitive to mesh refinement and time integration truncation error, although coarse meshes tend to damp out the time periodic behavior. The amplitude and frequency of the oscillation is sensitive to both mesh and time truncation errors.

Keywords: Finite Element Method, Navier-Stokes, Incompressible flow, Boussinesq approximation 


\section{Introduction}

This paper is a submission to the special session on "Computational Predictability

Of Natural Convection Flows in Enclosures". Refer to [1] for introductory material and a problem description.

\section{The MELT2D Code}

The MELT2D code was originally written to solve free and moving boundary problems in liquid metals processing. Details on the code and method can be found in [2]. All of the free-boundary features were turned off for the natural convection in a cavity problem presented here. With the appropriate dimensionless coefficients per the problem definition, the MELT2D code solves Eqns. (1)-(3) as given in [1].

A "straight" Galerkin Finite Element Method implementation of the NavierStokes and energy balance equations is used with velocity, pressure, and temperature as the primitive variables. The continuity equation constraint determines the pressure, as is typically done. The resulting system of nonlinear equations is solved simultaneously for all primitive variables with Newton's method. The linear equation system for each Newton step is solved using a direct frontal solver. 
The time-integration is performed for consistent mass and capacitance matrices using the second-order accurate implicit trapezoid rule. The time step size is automatically selected to maintain an estimate of the time integration truncation error below a user specified tolerance. More details on the time-stepping algorithm are given in [3]. A single Newton iteration is taken per time-step to solve the non-linear "corrector" equations. For sufficiently small error tolerances the solution change is small enough that multiple Newton steps are not required (for details, see [3]).

The element is the $Q_{2} Q_{1}$ element with bi-quadratic $C^{0}$ continuous velocity and temperature and bi-linear $C^{0}$ continuous pressure interpolation. The total number of unknowns for a rectangular mesh that is $n_{x}$ by $n_{y}$ grid points is:

$3 n_{x} n_{y}+\frac{n_{x}+1}{2} \sqrt{\frac{n_{y}+1}{2}} \sqrt{ }$

There are no artificial viscosity terms or special advection limiters used in the method.

\section{Problem Setup}


Calculations were run on three meshes indicated in Table 1. The meshes are graded with a two-sided 3:1 geometric spacing, i.e., the elements in the center are 3 times the size of elements at the walls. The boundary conditions are given in [1] with an additional specification of the pressure at the lower right corner $(x=W$, $y=0$ ) of the domain. Pressure specification at a point is required for this method to avoid a singular matrix. The CPU times reported in Table 1 are for a single matrix solve (1 per time step) using a $300 \mathrm{MHz}$ SGI Octane with the R12K processor.

Two different initial conditions were used. The first is a steady-state solution of the governing equations with the convection terms "turned off" by setting appropriate coefficients to zero, i.e., only the diffusion of energy and momentum terms contribute. This is a linear problem and is solved in a single iteration. The time-dependent calculation was then started with $R a=3.4 \times 10^{5}$ and $P r=0.71$ and all nonlinear terms "turned on". The startup transient showed wild fluctuations including a very complex flow field with up to 8 distinct cells at one time. The calculations were never continued to the point that a continuous periodic oscillatory mode was established. A second initial condition was devised to reduce the effect of the startup transient. A steady-state solution was found at $R a=3.2 \times 10^{5}$ and the time-dependent calculations were then started from this point 
(yes, it is possible to find a steady-state solution at $R a=3.2 \times 10^{5}$ ). The final timeperiodic behavior appeared to become fully established after about 1 unit of the diffusion time where the diffusion time is $\sqrt{R a \operatorname{Pr}}=491$.

\section{Results}

The compulsory results as outlined in [1] for the finest meshes M2 and M3 are given in Tables 2-4. Values reported for the amplitude of the oscillation are peakto-valley and were found by taking the difference between the maximum and minimum value over the time period used to compute the average and period. The period of the oscillation is peak-to-peak and was computed using a power spectrum code over the final 303 time units on M2 and the final 600 time units on M3. A previous series of calculations on $\mathrm{M} 1$ at $R a=3.2 \times 10^{5}$ showed that the timeperiodic behavior was damped out. Similar results are expected on M1 at $R a=3.4 \times 10^{5}$ but the calculations have not yet been carried out.

As expected, the amplitude of the oscillation appears to be more sensitive to the mesh than the average values. In most cases, differences in the averages between M2 and M3 occur in the third or fourth significant digit. The exception to this is the skewness for which the average value differs by almost $30 \%$ and the amplitude of the oscillation differs by almost a factor of 5 . The magnitude of the 
skewness divided by the temperature is actually smaller than the specified timetruncation error. The solution does appear to have a skew-unsymmetric mode, however, it cannot be quantified accurately from the current results. A plot of the skewness does show a time-periodic behavior and a power spectrum reveals the same oscillation period as all of the other quantities tabulated. Calculations with tighter time truncation error tolerances are warranted to further examine the skewness.

For both the M2 and M3 calculations the value of the specified time-truncation error was $5 \times 10^{-5}$. For both meshes, once the "steady" time-periodic behavior was established the time step size remained unchanged settling in to about 16 points per oscillation period. A calculation was run on M3 with the time-truncation error tolerance was specified as $1 \times 10^{-4}$ (a factor of 5 larger than the results in Tables 24). The temperature at point 1 has the same average temperature, the period of oscillation is 3.51 and the amplitude is 0.04688 (compare to the values given in Table 2). Apart from the skewness, the time-truncation error tolerance appears to be adequate. Calculations with smaller tolerances will be performed to confirm this. 
The temperature at point 1 from the M3 calculation is shown in Figure 1. Note that the solution settles into the "steady" time-periodic behavior in about 1 unit of the diffusion time. All of the other quantities in Tables 2-4 showed similar behavior. A secondary envelope appears around the primary oscillation in Figure 1 during the "steady" oscillation. This is actually a consequence of the oscillation period not being evenly divisible by the time step size. Figure 2 shows the temperature oscillation at point 1 on an expanded scale with the solution points marked. Note that the extrema of the oscillation depends on the position of the time points for a particular cycle.

\section{Conclusions}

Time periodic solutions were found for the natural convection of a $\operatorname{Pr}=0.71$ fluid in a differentially heated $8 \times 1$ cavity at $R a=3.4 \times 10^{5}$ using a "straight" Galerkin finite element method with the $Q_{2} Q_{1}$ element. As expected, the average values of various solution metrics were relatively insensitive to mesh refinement and time integration truncation error, although coarse meshes tend to damp out the time periodic behavior. The amplitude and frequency of the oscillation is sensitive to both mesh and time truncation errors and may not be fully resolved for the calculations run so far. A skew-unsymmetric mode appears to be active in the time periodic solutions found but probably cannot be quantified from the current 
calculations. Tighter time truncation error tolerances and further mesh refinements will be explored in subsequent calculations.

\section{Acknowledgement}

Work performed under the auspices of the U.S. Department of Energy by the Lawrence Livermore National Laboratory under Contract W-7405-ENG-48.

\section{References}

1 M.A. Christon, P.M. Gresho, S.B. Sutton, "Computational

Predictability of Natural Convection Flows in Enclosures", Special

Session, First M.I.T. Conference on Computational Fluid and Solid

Mechanics, Massachusetts Institute of Technology, Cambridge,

MA, June 12-14, 2001.

2 K.W. Westerberg, M.A. McClelland, B.A. Finlayson, "Finite

Element Analysis of Flow, Heat Transfer, and Free Interfaces in an

Electron-Beam Vaporization System for Metals", Int. J. Numer.

Methods Fluids, Vol 26, pp. 637-655, (1998).

3 K.W. Westerberg, C. Wiklof, B.A. Finlayson, "Time-Dependent

Finite-Element Models of Phase-Change Problems With Moving 
Heat Sources", Numer. Heat Transfer, Part B, Vol. 25, pp119-143, (1994). 
Table 1: Summary of meshes used for time-dependent calculations.

\begin{tabular}{|c|c|c|c|c|}
\hline \multirow{2}{*}{ Mesh } & \multicolumn{2}{|c|}{ Size (nx by ny) } & Unknowns & $\begin{array}{c}\text { CPU time } \\
(\mathrm{sec})\end{array}$ \\
\cline { 2 - 3 } & Elements & Nodal points & & 3.8 \\
\hline M1 & $16 \times 50$ & $33 \times 101$ & 10866 & 16.8 \\
\hline M2 & $24 \times 80$ & $49 \times 161$ & 25692 & 36.0 \\
\hline M3 & $30 \times 100$ & $61 \times 201$ & 39914 & \\
\hline
\end{tabular}


Table 2: Time history data for point 1 (except skewness and pressure differences) for meshes M2 and M3.

\begin{tabular}{|c|c|c|c|c|c|c|}
\hline \multirow[t]{2}{*}{ Quantity } & \multicolumn{3}{|c|}{$\begin{array}{l}\text { Mesh Resolution: } 49 \text { x } 161 \text { (M2) } \\
\text { Time Duration: } 303 \\
\text { Steps Per Period: } 16\end{array}$} & \multicolumn{3}{|c|}{$\begin{array}{l}\text { Mesh Resolution: } 61 \text { x } 201 \text { (M3) } \\
\text { Time Duration: } 600 \\
\text { Steps Per Period: } 16\end{array}$} \\
\hline & Average & $\begin{array}{l}\text { Amplitude } \\
(\mathrm{P}-\mathrm{V})\end{array}$ & $\begin{array}{l}\text { Period } \\
(\mathrm{P}-\mathrm{P})\end{array}$ & Average & $\begin{array}{l}\text { Amplitude } \\
(\mathrm{P}-\mathrm{V})\end{array}$ & $\begin{array}{l}\text { Period } \\
(\mathrm{P}-\mathrm{P})\end{array}$ \\
\hline X-Velocity & 0.05645 & 0.05734 & 3.44 & 0.05663 & 0.05825 & 3.41 \\
\hline Y-Velocity & 0.4617 & 0.08022 & 3.44 & 0.4620 & 0.08089 & 3.41 \\
\hline Temperature & 0.2655 & 0.04440 & 3.44 & 0.2655 & 0.04506 & 3.41 \\
\hline Skewness & $-0.798 \mathrm{E}-6$ & $4.69 \mathrm{E}-6$ & 3.44 & $-0.623 \mathrm{E}-6$ & $1.04 \mathrm{E}-6$ & 3.41 \\
\hline Streamfunction & 0.07366 & 0.007223 & 3.44 & 0.07357 & 0.007366 & 3.41 \\
\hline Vorticity & -2.401 & 1.130 & 3.44 & -2.337 & 1.151 & 3.41 \\
\hline$\Delta \mathrm{P}_{14}$ & $-0.1898 \mathrm{E}-2$ & 0.02206 & 3.44 & $-0.1809 \mathrm{E}-2$ & 0.02181 & 3.41 \\
\hline$\Delta \mathrm{P}_{51}$ & -0.5349 & 0.02501 & 3.44 & -0.5352 & 0.02496 & 3.41 \\
\hline$\Delta \mathrm{P}_{35}$ & 0.5368 & 0.01268 & 3.44 & 0.5370 & 0.01273 & 3.41 \\
\hline
\end{tabular}


Table 3: Wall Nusselt numbers. Note that the Nusselt number defined in Eqn. (16) of [1] is negative. Positive values are reported below.

\begin{tabular}{|c|c|c|c|c|c|c|}
\hline \multirow[t]{2}{*}{ Quantity } & \multicolumn{3}{|c|}{$\begin{array}{l}\text { Mesh Resolution: } 49 \text { x } 161 \text { (M2) } \\
\text { Time Duration: } 303 \\
\text { Steps Per Period: } 16\end{array}$} & \multicolumn{3}{|c|}{$\begin{array}{l}\text { Mesh Resolution: } 61 \text { x } 201 \text { (M3) } \\
\text { Time Duration: } 600 \\
\text { Steps Per Period: } 16\end{array}$} \\
\hline & Average & $\begin{array}{l}\text { Amplitude } \\
(\mathrm{P}-\mathrm{V})\end{array}$ & $\begin{array}{l}\text { Period } \\
(\mathrm{P}-\mathrm{P})\end{array}$ & Average & $\begin{array}{l}\text { Amplitude } \\
(\mathrm{P}-\mathrm{V})\end{array}$ & $\begin{array}{l}\text { Period } \\
(\mathrm{P}-\mathrm{P})\end{array}$ \\
\hline $\mathrm{Nu}(\mathrm{x}=0)$ & 4.593 & 0.007568 & 3.44 & 4.587 & 0.007600 & 3.41 \\
\hline $\mathrm{Nu}(\mathrm{x}=\mathrm{W})$ & 4.593 & 0.007570 & 3.44 & 4.587 & 0.007602 & 3.41 \\
\hline
\end{tabular}


Table 4: Velocity and vorticity metrics.

\begin{tabular}{|l|l|l|l|l|l|c|}
\hline Quantity & \multicolumn{3}{|l|}{$\begin{array}{l}\text { Mesh Resolution: 49 x 161 (M2) } \\
\text { Time Duration: 303 } \\
\text { Steps Per Period: 16 }\end{array}$} & \multicolumn{2}{l}{$\begin{array}{l}\text { Mesh Resolution: 61 x 201 (M3) } \\
\text { Time Duration: 600 } \\
\text { Steps Per Period: 16 }\end{array}$} \\
\cline { 2 - 7 } & Average & $\begin{array}{l}\text { Amplitude } \\
(\mathrm{P}-\mathrm{V})\end{array}$ & $\begin{array}{l}\text { Period } \\
(\mathrm{P}-\mathrm{P})\end{array}$ & Average & $\begin{array}{l}\text { Amplitude } \\
(\mathrm{P}-\mathrm{V})\end{array}$ & $\begin{array}{l}\text { Period } \\
\text { (P-P) }\end{array}$ \\
\hline Velocity Metric & 0.2396 & $3.54 \mathrm{E}-5$ & 3.44 & 0.2396 & $3.59 \mathrm{E}-5$ & 3.41 \\
\hline Enstrophy & 3.017 & 0.003313 & 3.44 & 3.017 & 0.003353 & 3.41 \\
\hline
\end{tabular}




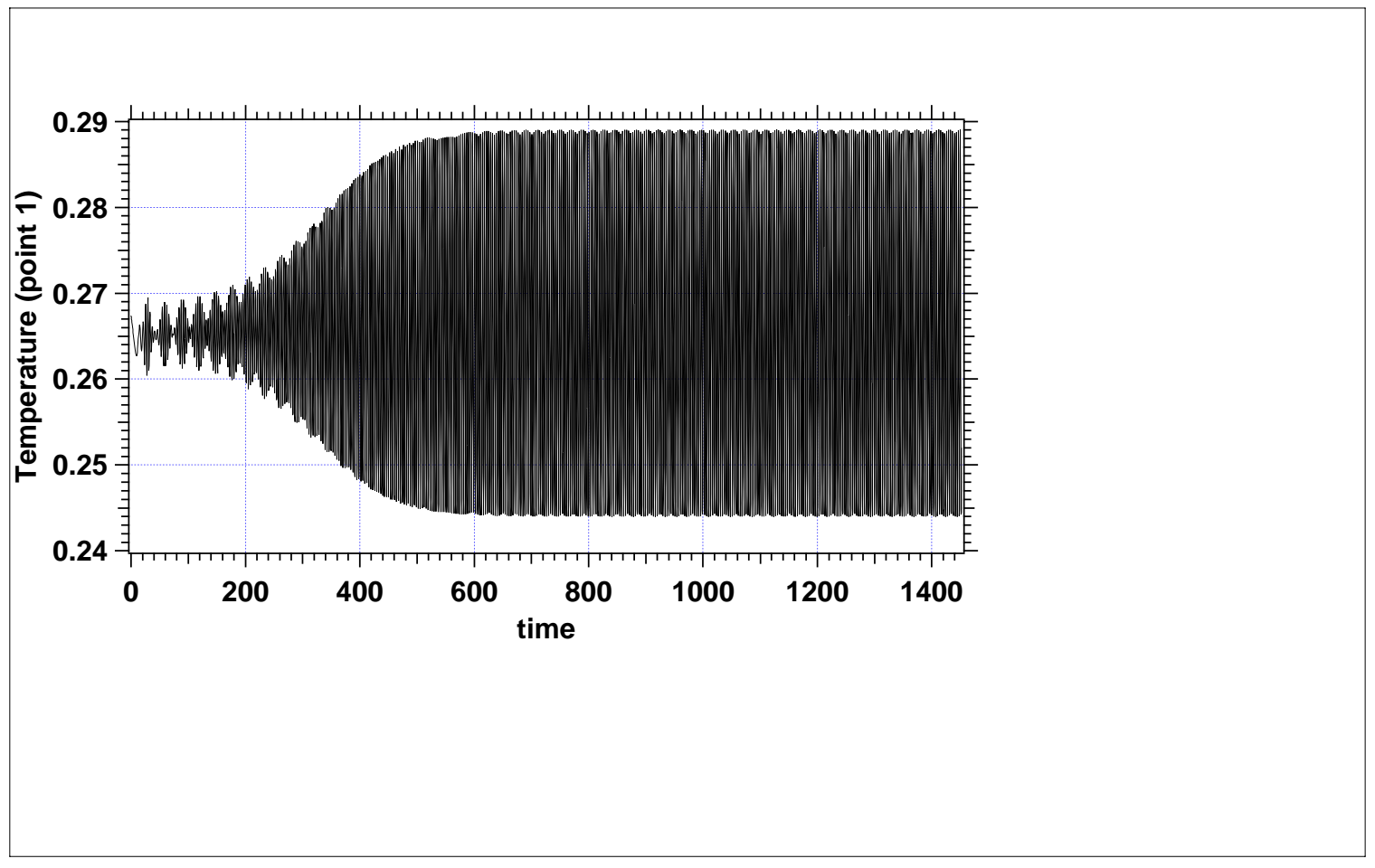

Figure 1: Time history of temperature at point 1. 


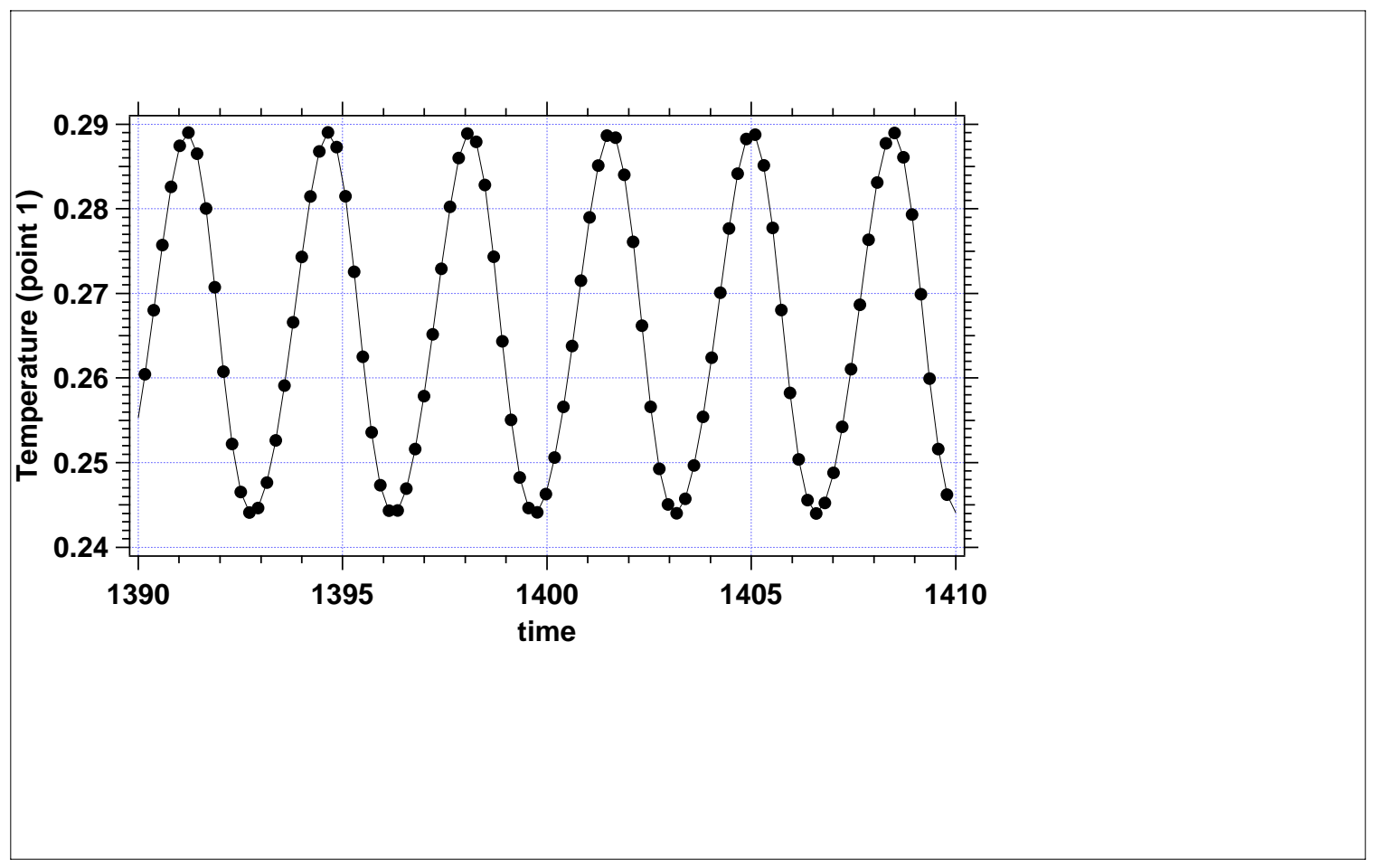

Figure 2: Time history of temperature at point 1 on expanded scale. Solution points are marked. 